\title{
Role of immature gastrointestinal functions in newborns with necrotizing enterocolitis (NEC)
}

\author{
Sonja Stutte, Verena Frost, Ebu Alsat, Heiko Reutter, Andreas Müller, Soyhan Bagci
}

Department of Neonatology and Pediatric Intensive Care, Children's Hospital, University of Bonn, Germany

\section{Background/Aim}

It has been proposed that the relative immaturity of key gastrointestinal functions such as digestion, absorption and motility predispose to necrotizing enterocolitis (NEC).

The aim of the study was to evaluate the role of immature gastointestinal functions in newborns with NEC.

\section{Patients and Methods}

In our retrospective case-control-study we included 65 newborns (NEC-G) with NEC $\geq$ stage 2 a according to the classification of Bell as well as 130 healthy control newborns. Gastrointestinal functions were assessed by measuring gastric residual volumes prior to feeding (GRVs, total amount per day, amount per $\mathrm{kg}$ and percentage of previous feeding), aspect of residuals (day of first manifestation, amount and frequency of bilious or hemorrhagic residuals), day of first meconium and stool frequency. For each case-control pair (C-G), we used day $0(\mathrm{~d} 0)$ as the same postnatal day at which NEC developed in the case newborn. Data were collected for all newborns from day of birth (day Birth $(\mathrm{dB}))$ to $\mathrm{d} 0$.

\begin{tabular}{|l|c|c|c|}
\hline & $\begin{array}{c}\text { NEC-G } \\
(n=65)\end{array}$ & $\begin{array}{c}\text { C-G } \\
(n=130)\end{array}$ & p-Value \\
\hline \begin{tabular}{l|c|c|} 
Gestational age \\
$(\text { Week })^{*}$
\end{tabular} & 27.1 & 27.5 & n. s. \\
\hline Birthweight $(g){ }^{*}$ & 840 & 860 & n. s. \\
\hline & $(24.7-30.7)$ & $(25.0-30.6)$ & \\
\hline * Median (IQR), n. S.: non significant & \\
\hline Tab. 1 Clinical characteristics & \\
\hline
\end{tabular}

\section{Results}

On average, NEC occurred at day 9 of life. From dB to d1, there was no significant difference concerning amount of GRVs, aspect of residuals, day of first meconium and stool frequency between both groups (Table 2). Maximal differences of GRVs between newborns with NEC and control newborns were measured only at d0 (NEC vs. Control, $5.9 \mathrm{ml} / \mathrm{kg} / \mathrm{d}$ vs. $2.6 \mathrm{ml} / \mathrm{kg} / \mathrm{d}, \mathrm{p}<0.001)($ Figure 1).

\section{Conclusion}

We found no relationship between immature gastrointestinal functions and occurrence of NEC in our collective. Neither the amount nor the aspect of GRVs seem to be useful early clinical predictors for NEC.

\begin{tabular}{|c|c|c|c|}
\hline Gastric residual & $\begin{array}{l}\text { NEC-G } \\
(n=64)\end{array}$ & $\begin{array}{c}C-G \\
(n=129)\end{array}$ & p-Value \\
\hline Bloody, n (\%) & $30(46,9)$ & $62(48,1)$ & n. s. \\
\hline Total days* & $2(1-3)$ & $1(1-3)$ & n. s. \\
\hline First manifestation ${ }^{a}$ & $3(1-8)$ & $3(1-5)$ & n. s. \\
\hline Bilious, n (\%) & $44(68,8)$ & $77(59,7)$ & n. s. \\
\hline Total days* & $3(1-4)$ & $2(1-3)$ & n. s. \\
\hline First manifestationa & $3(2-5)$ & $2(2-4)$ & n. s. \\
\hline \multicolumn{4}{|c|}{$\begin{array}{l}\text { * Median (IQR), n. s.: non significant } \\
\text { a Day of life }\end{array}$} \\
\hline
\end{tabular}

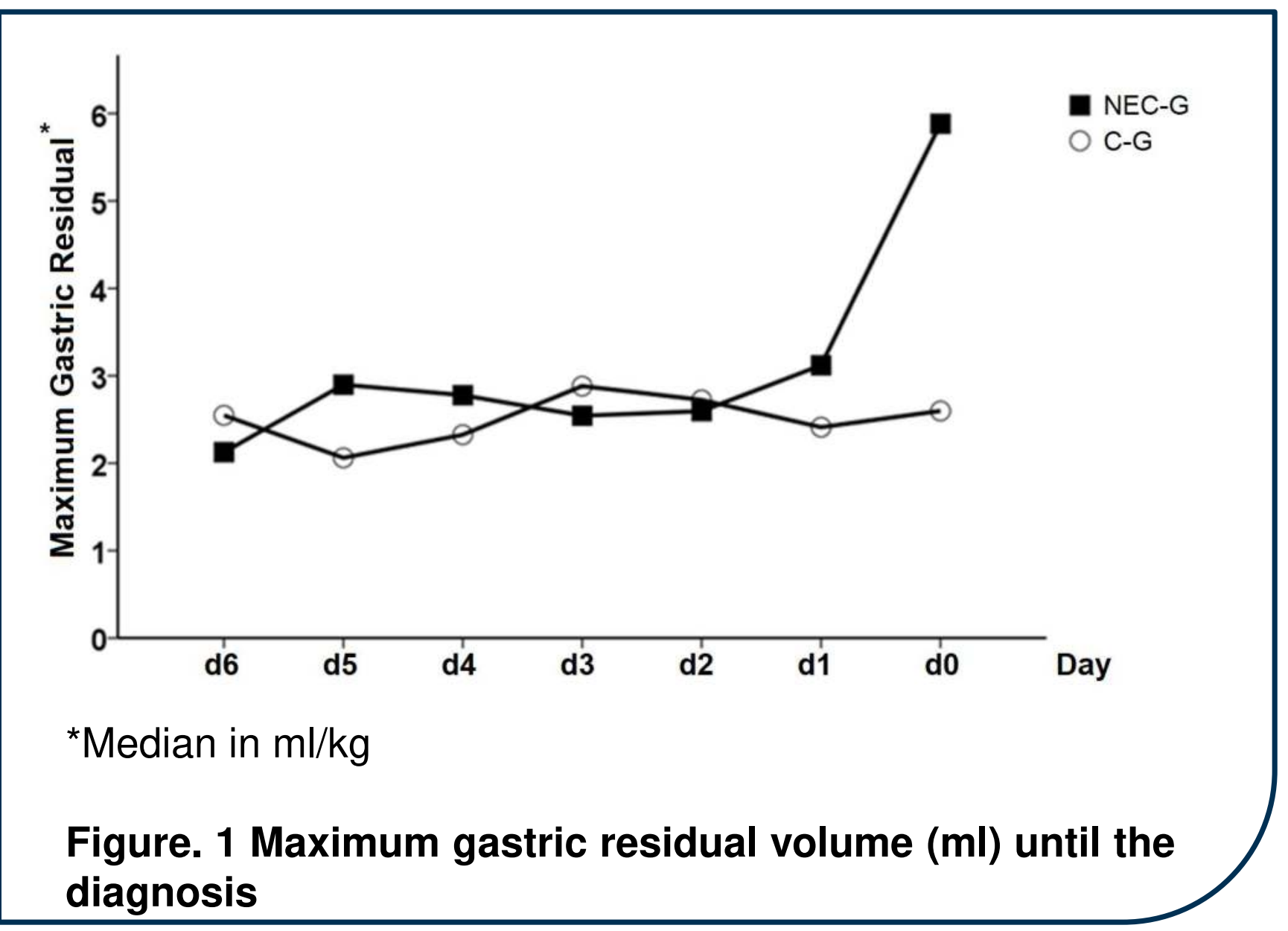

